\title{
Infrared (810-nm) low-level laser therapy on rat experimental knee inflammation
}

\author{
Rodney Capp Pallotta • Jan Magnus Bjordal • Lúcio Frigo • \\ Ernesto Cesar Pinto Leal Junior • Simone Teixeira • Rodrigo Labat Marcos • \\ Luciano Ramos • Felipe de Moura Messias • Rodrigo Álvaro Brandão Lopes-Martins
}

Received: 3 November 2010 / Accepted: 22 February 2011 /Published online: 12 April 2011

(C) The Author(s) 2011. This article is published with open access at Springerlink.com

\begin{abstract}
Arthritis of the knee is the most common type of joint inflammatory disorder and it is associated with pain and inflammation of the joint capsule. Few studies address the effects of the 810-nm laser in such conditions. Here we investigated the effects of low-level laser therapy (LLLT; infrared, $810-\mathrm{nm})$ in experimentally induced rat knee inflammation. Thirty male Wistar rats $(230-250 \mathrm{~g})$ were anesthetized and injected with carrageenan by an intraarticular route. After 6 and 12 h, all animals were killed by
\end{abstract}

Financial support FAPESP Grants 2005/02117-6

R. C. Pallotta $\cdot$ S. Teixeira $\cdot$ R. L. Marcos $\cdot$ L. Ramos $\cdot$

R. Á. B. Lopes-Martins

Laboratory of Pharmacology and Experimental Therapeutics,

Department of Pharmacology, Institute of Biomedical Sciences,

University of São Paulo,

São Paulo, SP, Brazil 05508-900

J. M. Bjordal

Section of Evidence Based Research, Bergen University College,

Bergen, Norway

\section{Frigo}

Biological Sciences and Health Center,

Cruzeiro do Sul University,

São Paulo, SP, Brazil 08060-070

E. C. P. Leal Junior · F. de Moura Messias •

R. Á. B. Lopes-Martins

Post Graduate Program in Rehabilitation

Sciences - Nove de Julho University,

São Paulo, SP, Brazil

R. Á. B. Lopes-Martins $(\bowtie)$

Laboratory of Pharmacology and Phototherapy of Inflammation, Department of Pharmacology, Institute of Biomedical Sciences, University of São Paulo,

Av. Prof. Lineu Prestes, 1524, Butantan,

São Paulo, SP, Brazil 05508-900

e-mail: rmartins@icb.usp.br
$\mathrm{CO}_{2}$ inhalation and the articular cavity was washed for cellular and biochemical analysis. Articular tissue was carefully removed for real-time PCR analysis in order to evaluate COX-1 and COX-2 expression. LLLT was able to significantly inhibit the total number of leukocytes, as well as the myeloperoxidase activity with 1,3 , and $6 \mathrm{~J}$ (Joules) of energy. This result was corroborated by cell counting showing the reduction of polymorphonuclear cells at the inflammatory site. Vascular extravasation was significantly inhibited at the higher dose of energy of $10 \mathrm{~J}$. Both COX-1 and 2 gene expression were significantly enhanced by laser irradiation while $\mathrm{PGE}_{2}$ production was inhibited. Low-level laser therapy operating at $810 \mathrm{~nm}$ markedly reduced inflammatory signs of inflammation but increased COX-1 and 2 gene expression. Further studies are necessary to investigate the possible production of antiinflammatory mediators by COX enzymes induced by laser irradiation in knee inflammation.

Keywords LLLT · Laser · Arthritis · Inflammation · Knee

\section{Introduction}

Arthritis is considered one of the major causes of chronic disability in the elderly population, affecting diarthrodial joints. Clinical symptoms are characterized by pain, reduced range of movement, crepitus, tenderness, and inflammation. Social and financial consequences of this illness tend to be higher as this population parcel is markedly growing [1-3].

Although arthritis may be initiated by impact loading and other mechanical agents acting on the joint, proinflammatory eicosanoids and cytokines play an important role in the progression of the disease $[4,5]$. 
Increasing evidence indicates that cartilage degeneration results from inflammatory process at the molecular level. Activated inflammatory cells and chondrocytes produce a wide range of cytokines and chemokines, such as interleukin-1 (IL-1), IL-6, IL-8, IL-17, and IL-18, etc. In addition, reactive oxygen species (ROS) and lipid-derived mediators products, such as prostaglandins and leukotrienes, increases chondrocyte catabolic activity [2, 4, 5].

IL-1 and TNF- $\alpha$ are the most extensive studied metabolites. IL-1 is found in significant levels in osteoarthritis synovial fluid and type I IL-1 receptor is increased expressed on osteoarthritis chondrocyte. It is capable of suppressing type II collagen synthesis and suppress proteoglycan synthesis [4, 5].

IL-1 and TNF- $\alpha$ are also important regulators of metalloproteinase (MMP) gene expression and protein synthesis in osteoarthritis [5-7]. Additionally, TNF- $\alpha$ is also found in synovial fluid and its receptor TFR1 is up-regulated in osteoarthritis. The production of prostanoids such as leukotriens and prostaglandins is also specially involved in osteoarthritis-related pain and disability [8].

Arthritis therapies are based on relieving pain, improving the range of motion, and promoting partial tissue regeneration. Current therapeutic strategies include surgical procedures and pharmacological and non-pharmacological management. Surgical procedures are only considered after more conservative therapies have failed, and it includes osteotomy, arthroscopy management, grafting, arthrodesis, and arthroplasty. Besides analgesics (opiate and non-opioid) and chondroitin, glucosamine, sodium hyaluronate compounds, the anti-inflammatory drugs (corticosteroids and non-steroidal) are the most widely used drugs, despite that a panel of experts has ranked oral non-steroidal antiinflammatory drugs (NSAIDs) as the most toxic therapy in knee osteoarthritis, followed by corticosteroid injections, paracetamol, topical NSAIDs, chondroitin, and glucosamine sulphate [3, 9].

The search for less toxic non-pharmacological alternatives agents in arthritis management suffers from lack of interest and funding, but low-level laser therapy (LLLT) is about to be taken more seriously by clinicians. We recently demonstrated that LLLT is effective in reducing non-specific neck pain $[10,11]$ and is beginning to be considered a potential alternative to drugs.

The bulk of new and increasing evidence shows that LLLT is no longer a mythical alternative therapy with diffuse and hypothetical mechanisms of biological action, but a therapy that has distinct biophysical properties and dose-dependent biological mechanisms of action [12].

Several animal and human trials have been performed that show the modulatory effect of laser radiation on inflammatory markers $\left(\mathrm{PGE}_{2}, \mathrm{TNF}-\alpha\right.$, IL- $1 \beta$, plasminogen activator) and on the inflammatory process itself (reducing edema, hemorrhagic formation, necrosis, neutrophils influx) [12, 13].

In this perspective, the present study was designed to investigate the effect of low-level laser therapy on edema formation, leucocyte influx, myeloperoxidase activity, COX-1 and COX-2 gene expression, residues, IL-1 and $\mathrm{PGE}_{2}$ quantification in rat-induced knee inflammation in rats. In other words, our main hypothesis is that LLLT can act as an effective therapeutic alternative to treat joint inflammatory conditions.

\section{Materials and methods}

Animals

All experimental procedures were submitted and approved by the Ethical Committee of the University of São Paulo.

Male Wistar rats $(250 \mathrm{~g})$ were housed five per cage before the experimental procedure. Food and water were provided ad libitum throughout the experimental protocol. Rats were anesthetized with inhalatory halothane to allow inflammatory stimuli injection. All pre-operative procedures were performed to prevent discomfort and to avoid any infection. The animals were killed by $\mathrm{CO}_{2}$ inhalation at different times.

\section{Procedures}

\section{Induction of acute arthritis}

Animals were anesthetized with an intraperitoneal injection of ketamine $(52 \mathrm{mg} / \mathrm{kg})$ and xylazine $(0.5 \mathrm{mg} / \mathrm{kg})$, and trichotomized at the region of the left side. Initially $100 \mu \mathrm{l}$ of kaolin (3\%, Sigma-Aldrich) plus carrageenan $(3 \%)$ dissolved in sterile saline solution $(\mathrm{NaCl}, 0.9 \%)$ was injected into the joint using a micro syringe $(300 \mu \mathrm{l})$. The bevel of the needle was positioned medially to the patellar ligament, performing the puncture towards the joint surface of the femur.

\section{Experimental groups}

Each group was composed of five animals randomly divided into six groups as follows:

- Control group - The animals received kaolin + carrageenan.

- Diclofenac group - The animals received kaolin + carrageenan and pre-treated with sodium diclofenac (1 mg/kg; IM, 30 min prior inflammatory stimulus). 
- $1.0 \mathrm{~J}$ group - The animals received the induction of inflammation and after $1 \mathrm{~h}$ received laser irradiation - $1.0 \mathrm{~J}$.

- $3.0 \mathrm{~J}$ group - The animals received the induction of inflammation and after $1 \mathrm{~h}$ received laser irradiation $3.0 \mathrm{~J}$.

- $6.0 \mathrm{~J}$ group - The animals received the induction of inflammation and after $1 \mathrm{~h}$ received laser irradiation $6.0 \mathrm{~J}$.

- $\quad 10.0 \mathrm{~J}$ group - The animals received the induction of inflammation and after $1 \mathrm{~h}$ received laser irradiation $10.0 \mathrm{~J}$.

\section{Low-level laser therapy procedure}

LLLT was performed $1 \mathrm{~h}$ after carrageenan + kaolin injection using an infrared laser unit (DMC, São Carlos, Brazil). The laser unit emitted a continuous optical output of $100 \mathrm{~mW}$ with a wavelength of $810 \mathrm{~nm}$ and a spot size area of $0.028 \mathrm{~cm}^{2}$, which gave a power density of $5 \mathrm{~W} / \mathrm{cm}^{2}$. The optical output of the laser unit was measured before, halfway through, and after the experiment. Laser irradiation was performed in skin contact at the site of injection with doses of $1,3,6$, and $10 \mathrm{~J}$ with corresponding irradiation times of $10,30,60$, and $100 \mathrm{~s}$, and energy densities of 50, 150,300 , and $500 \mathrm{~J} / \mathrm{cm}^{2}$, respectively.

\section{Cellular, biochemical, and molecular analysis}

All analyses were performed by an observer who was blinded to group allocation. Initial analysis was performed at Section of Pharmacology, ICB at University of São Paulo, Brazil. To ensure consistency in analyses and reproducibility of results, two other laboratories at University of São Paulo, Brazil, duplicated the analyses.

\section{Joint cavity wash}

The joint wash was obtained by injection and aspiration of final volume of $300 \mu \mathrm{l}(3 \times 100 \mu \mathrm{l})$ of solution PBS + EDTA $(4 \mu \mathrm{M})$ (Ultrafine $29 \mathrm{G}$, BD). The joint washings were transferred to Eppendorf tubes and stored at $-80^{\circ} \mathrm{C}$ until the time of biochemical test.

The total number of cells counting was performed taking $20 \mu \mathrm{l}$ from lavage fluid diluted in Turkey liquid (380 $\mu \mathrm{l})$. A Neubauer chamber was used under an optical microscope (Carl Zeiss) with $40 \times$ amplification. The results were expressed as a total number of leucocytes per cavity. For differential leukocyte cell counts (mononuclear and neutrophil cells), we used the same microscope with a higher $(100 \times)$ amplification. For the leukocyte differential cell counting, 100-ml aliquots from cells suspension were used for centrifugation $(2,000 \mathrm{rpm}, \mathrm{T}=400 \mathrm{~s}$, rise time $=18 \mathrm{~s}$, stop time $=11 \mathrm{~s}$ ).
Vascular permeability - Evans Blue dye

An Evans Blue dye (25 mg/ml; Merck) was dissolved in saline solution and then filtered in a sterilized membrane (0.22 $\mathrm{m}$; Millipore) and conserved in at $4^{\circ} \mathrm{C}$.

Animals were previously anesthetized with halothane and then injected intra-articularly with the Evans Blue dye, $1 \mathrm{~h}$ before euthanasia. The animals were killed by halothane super dose. After the killing, the joint was washed and exudate recovered in a glass tube in formamide solution (Merck article 9684,1000, $4 \mathrm{ml} / \mathrm{g}$ ) for dye extraction. A 150 - $\mu$ l sample from each tube was used for determination of Evans Blue concentrations (BIOTEK Spectrophotometer 618-620 nm).

Myeloperoxidase activity (MPO)

In order to determine MPO levels, $50 \mu$ l of exudate was added to $200 \mu \mathrm{l}$ of potassium phosphate buffer $(\mathrm{pH} 6.0$ ), containing $0.164 \mathrm{mg} / \mathrm{ml}$ of $o$-dianisidine dihydrochloride (Sigma Chemical Co., St. Louis, MO, USA) and $0.0005 \%$ of hydrogen peroxide (Merck, Darmstadt, Alemanha). The absorbance was measured in an ELISA scanner (Espectra max plus 384, Sunnyvale, CA, USA) at $460 \mathrm{~nm}$ for $20 \mathrm{~min}$, with recordings made at 20 -s intervals. Graphs showing the absorbance variation as a function of time were obtained and the Vmax/sec was calculated from these graphs. The time interval where the measurements of absorbance variation showed linearity was chosen from the graph (optical density or absorbance) as a function of time in seconds (corresponding to the value of $\mathrm{r} 2$ closer to 1 ), obtaining the value Vmax/sec. The mean of the duplicates was calculated and divided by the amount of tissue in each plate well (each $10 \mu \mathrm{l}$ of homogenate correspond to $0.5 \mathrm{mg}$ of tissue). The MPO activity unit is defined as the degradation in micromol $(\mu \mathrm{mol})$ of $\mathrm{H}_{2} \mathrm{O}_{2}$ per minute. Considering that $1 \mu \mathrm{mol}$ of $\mathrm{H}_{2} \mathrm{O}_{2}$ per minute corresponds to a variation of $0.0113 \mathrm{AU}$ (absorbance units), the activity of MPO was expressed in MPO units and corrected by the amount of tissue (mg) added to the assay (U/mg). Statistical analyses of the MPO levels were performed by Student's $t$ test, using a significance level of $0.05 \%$.

RNA isolation and real-time PCR analysis

At the selected time-points, the joint tissues were dissected, frozen in liquid nitrogen, and stored at $-80^{\circ} \mathrm{C}$. Total RNA was isolated in the Trizol reagent, according to the manufacturer's instructions.

DNase I was employed to digest DNA to obtain RNA purification and the integrity of RNA was verified by agarose gel electrophoresis. Total RNA $(2 \mu \mathrm{g})$ was used for first-strand cDNA synthesis [reverse transcriptase (RT)] 
using SuperScript II. In addition, RNaseOUT was also added to protect the RNA during this process. Three pooled RNA aliquots were routinely sham reverse transcribed (i.e., reverse transcriptase omitted) to ensure the absence of DNA contaminants. Diluted RT samples $(1: 10)$ were submitted to real-time PCR amplification using Platinum Sybr QPCR Supermix-UDG and specific oligonucleotides for COX-1 (forward: CCGTGCGAGTACAGTCACAT; reverse: CCTCACCAGTCATTCCCTGT) and COX-2 (forward: AGATCAGAAGCGAGGACCTG; reverse: CCATCCTG GAAAAGTCGAAG). Beta-actin was used as an internal control (forward: AAGATTTGGCACCACACTTTC TACA; reverse: CGGTGAGCAGCACAGGGT).

The conditions for PCR were as follows: $50^{\circ} \mathrm{C}, 2 \mathrm{~min}$; $95^{\circ} \mathrm{C}, 2 \mathrm{~min}$, followed by 30 cycles of $95^{\circ} \mathrm{C}, 15 \mathrm{~s} ; 60^{\circ} \mathrm{C}$, $1 \mathrm{~min}$, and $72^{\circ} \mathrm{C}, 15 \mathrm{~s}$. Ct values were recorded for each gene, the results of genes of interest were normalized to results obtained with the internal control gene. ddCT were calculated and the results are expressed as fold increase. All oligonucleotides and reagents utilized in this protocol were purchased from Invitrogen Co., USA.

$\mathrm{PGE}_{2}$ and cytokines analysis

$\mathrm{PGE}_{2}$ and cytokines generation were analyzed and determined according to the manufacturer's instructions by ELISA (R \& D Systems, Minneapolis, MN, USA).

\section{Outcomes}

The following outcomes were analyzed in this study: leukocyte, neutrophils, and mononuclear cells counting; myeloperoxidase activity; vascular permeability; IL-1, IL-6, and $\mathrm{PGE}_{2}$ (ELISA); and gene expression of COX-1 and COX-2 (real-time PCR analysis, from joint tissue and joint fluid).

\section{Statistical analysis}

A blinded observer unaware of the allocation to groups performed the statistical analysis. Data are expressed as mean and standard error $( \pm)$ of the mean (SEM). All data were statistically evaluated by analysis of variance (ANOVA), followed by the Newman-Keuls-Student's test. Values with $p<0.05$ were considered to be statistically significant.

\section{Results}

Inflammatory cell accumulation

Three hours after induction of inflammation we could observe that both LLLT (1.0 and $3.0 \mathrm{~J}$ ) as well as diclofenac significantly reduced the total number of leukocytes (Fig. 1a). After six hours, LLLT at the energy doses of 6.0 and $10.0 \mathrm{~J}$ significantly reduced the total number of leukocytes in the knee joint (Fig. 1b).

Regarding the neutrophils, one more time we could observe that both the diclofenac and LLLT groups treated with $3.0,6.0$, and $10.0 \mathrm{~J}$ significantly reduced $(p<0.001)$ the cell accumulation (Fig. 2a).

The number of mononuclear cells was significantly higher in all treated groups when compared to control (Fig. 2b).

Evans Blue dye extravasation

Figure 3a shows the amount of Evans Blue dye extravasation $6 \mathrm{~h}$ after induction of inflammation. Only the diclofenac and 10.0 J LLLT groups were effective in reducing Evans Blue extravasation $(p<0.05)$.

Myeloperoxidase activity (MPO)

Three hours after the induction of inflammation, the energy doses of laser of $6.0 \mathrm{~J}$ and $10.0 \mathrm{~J}$ doses significantly inhibited the MPO activity. Interestingly, the other laser
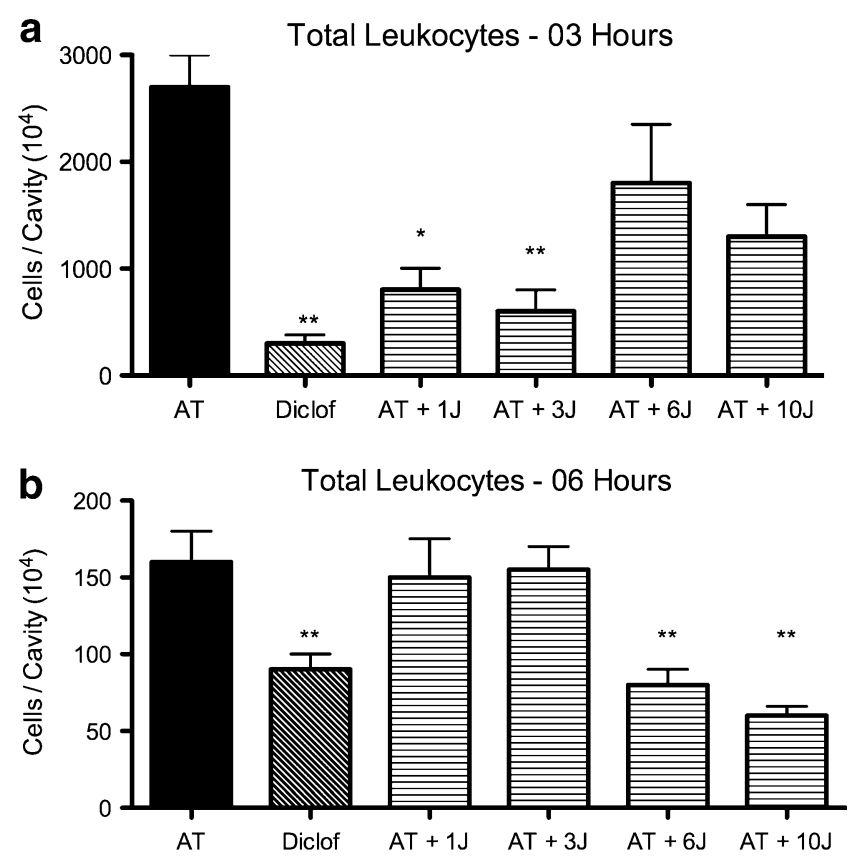

Fig. 1 Analysis of articular wash 3 and $6 \mathrm{~h}$ after induced inflammation. a Total number of leukocytes in articular lavage fluid after $3 \mathrm{~h}$ in the control group and after LLLT ( $n=6$ animals per group $\left({ }^{*} p<0.05\right)\left({ }^{* *} p<0.001\right)$. b Total number of leukocytes in articular lavage fluid after $6 \mathrm{~h}$ in the control group and after LLLT $(n=6$ animals per group arthritis group (AT); the arthritis group treated with diclofenac (Diclof); the arthritis group treated with $1 \mathrm{~J}$ LLLT (AT+ $1 \mathrm{~J}$ ); the arthritis group treated with $3 \mathrm{~J}$ LLLT $(\mathrm{AT}+3 \mathrm{~J})$; the arthritis group treated with $6 \mathrm{~J}$ LLLT $(\mathrm{AT}+6 \mathrm{~J}$ ); the arthritis group treated with $10 \mathrm{~J}$ LLLT $(\mathrm{AT}+10 \mathrm{~J})$. Results are expressed as mean $( \pm \mathrm{SEM})$ 

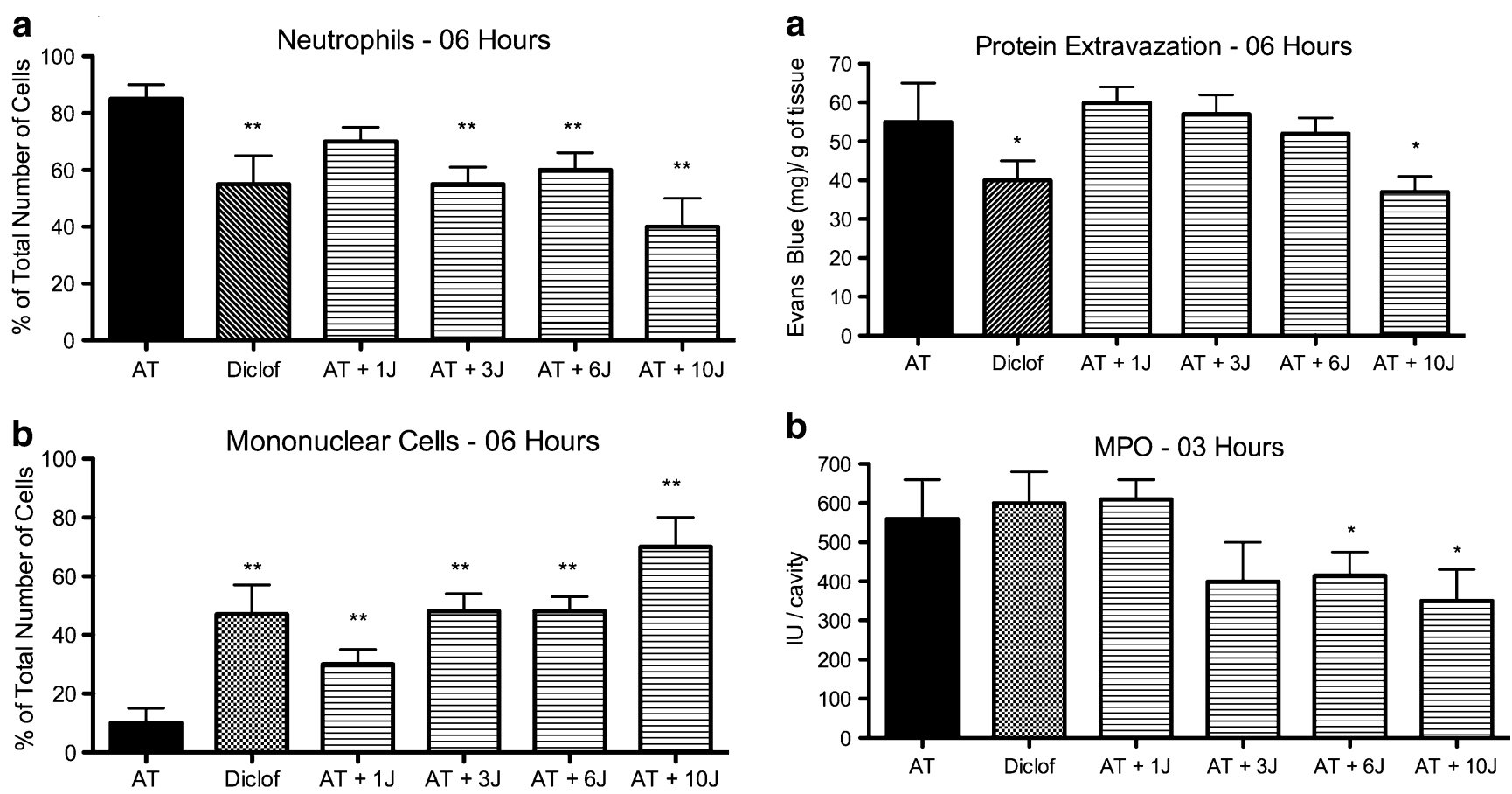

Fig. 2 a The number of neutrophils in the articular wash fluid 6 $\mathrm{h}$ after induced inflammation in the control group and after LLLT. b The number of mononuclear cells in the articular wash fluid 6 $\mathrm{h}$ after induced inflammation in the control group and after LLLT ( $n=6$ animals per group). Arthritis group (AT); arthritis group treated with diclofenac (Diclof); arthritis group treated with $1 \mathrm{~J}$ LLLT (AT+1 J); arthritis group treated with $3 \mathrm{~J}$ LLLT (AT+3 J); arthritis group treated with $6 \mathrm{~J}$ LLLT $(\mathrm{AT}+6 \mathrm{~J})$; arthritis group treated with $10 \mathrm{~J}$ LLLT $(\mathrm{AT}+10 \mathrm{~J})$. Results are expressed as mean $\pm \mathrm{SEM}$ $(* * p<0.001)$

energies as well as the diclofenac treatment did not present significant inhibition of MPO activity (Fig. 3b).

On the other hand, $6 \mathrm{~h}$ after the induction of inflammation, all experimental groups were able to produce a significant inhibition of MPO when compared do the control group (Fig. 3c).

\section{COX-1 and COX-2 gene expression in joint tissue}

Figure $4 \mathrm{a}$ and $\mathrm{b}$ shows the RNA expression of COX-1 and COX-2 enzymes, respectively, in joint tissue. We observed that the groups treated with LLLT with 3.0 and $10.0 \mathrm{~J}$ presented a significant increase of COX-1 and COX-2 RNA expression when compared to the control and diclofenac groups. The $6.0 \mathrm{~J}$ group just presented significant increase in COX-2 expression compared to control and diclofenac groups.

\section{COX-1 and COX-2 gene expression in joint fluid}

The energy dose of $3.0 \mathrm{~J}$ significantly increased the COX-1 expression in joint fluid when compared to the control and other experimental groups. On the other hand, we could not

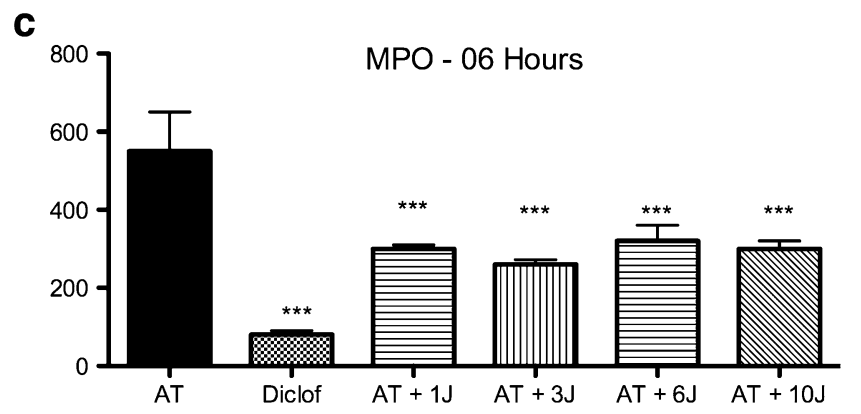

Fig. 3 a The protein extravasation as an indicator of vascular permeability $6 \mathrm{~h}$ after induced inflammation. b The activity of myeloperoxidase 3 $\mathrm{h}$ after induced inflammation in the control and treated groups. c The activity of myeloperoxidase $6 \mathrm{~h}$ after induced inflammation in control and treated groups $(* p<0.05)(* * * p<0.001)$. Arthritis group (AT); arthritis group treated with diclofenac (Diclof); arthritis group treated with $1 \mathrm{~J}$ LLLT (AT+1 J); arthritis group treated with $3 \mathrm{~J}$ LLLT (AT+3 J); arthritis group treated with $6 \mathrm{~J}$ LLLT $(\mathrm{AT}+6 \mathrm{~J})$; arthritis group treated with $10 \mathrm{~J}$ LLLT $(\mathrm{AT}+10 \mathrm{~J})$. Results are expressed as mean \pm SEM

observe any difference between all the tested groups regarding to COX-2 expression. These results can be visualized respectively in Fig. 5a and b.

\section{Cytokines}

Interleukin-1 We observed that diclofenac and LLLT groups (1.0 J and $6.0 \mathrm{~J}$ of energy doses) presented a significant inhibition of IL-1 levels in joint fluid (Fig. 6a)

Interleukin-6 The levels of IL-6 in joint fluid were significantly reduced in diclofenac as well as in LLLT groups $(1.0,3.0$, and $6.0 \mathrm{~J}$ of energy) but not with $10.0 \mathrm{~J}$ when compared to the control group (Fig. 6b). 

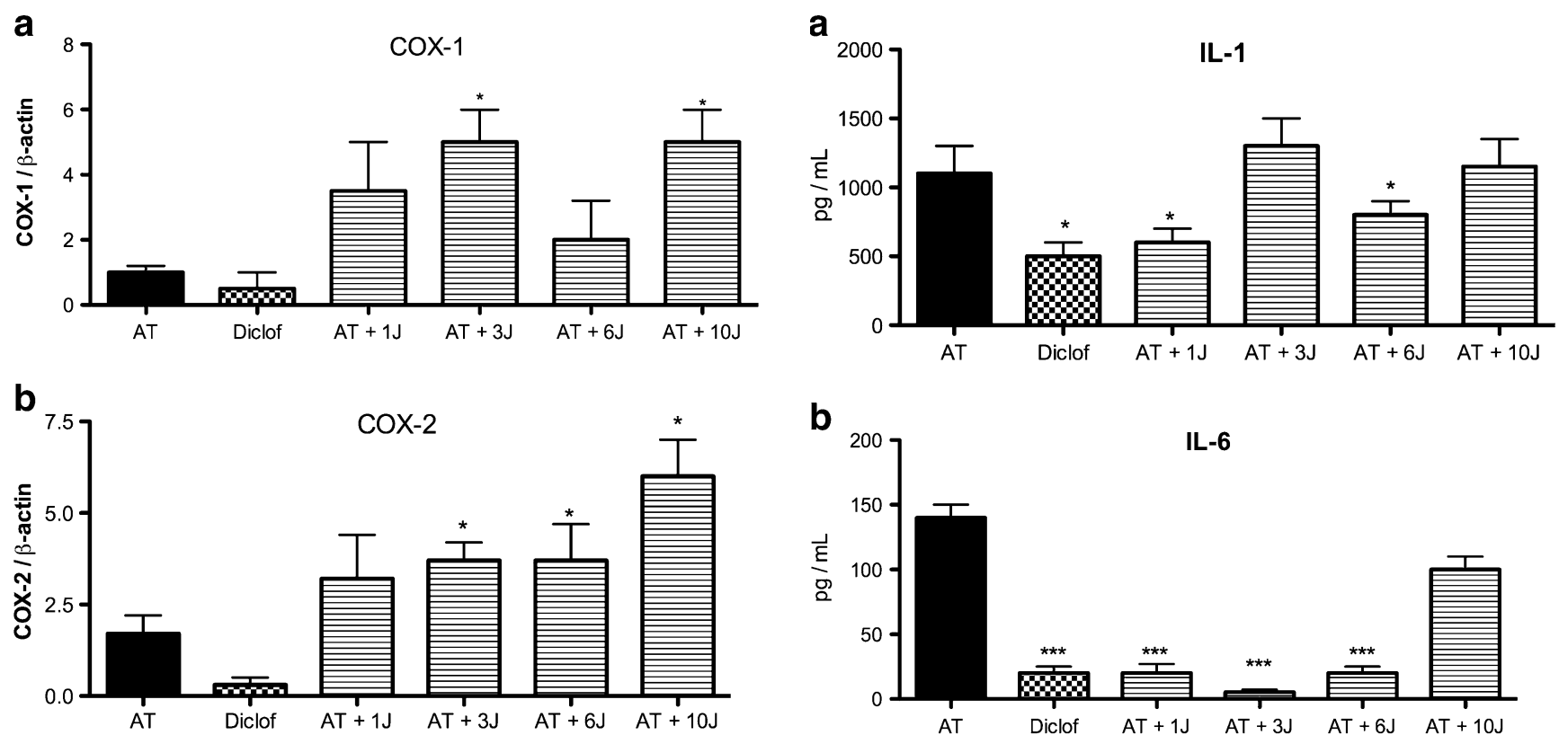

Fig. 4 a The RNA expression of COX-1 enzyme measured by realtime PCR in joint cartilage. $\mathbf{b}$ The RNA expression of COX-2 enzyme measured by real-time PCR in joint cartilage ( $n=6$ animals per group $\left({ }^{*} p<0.01\right)$. Arthritis group (AT); arthritis group treated with diclofenac (Diclof); arthritis group treated with $1 \mathrm{~J}$ LLLT $(\mathrm{AT}+1 \mathrm{~J})$; arthritis group treated with $3 \mathrm{~J}$ LLLT $(\mathrm{AT}+3 \mathrm{~J})$; arthritis group treated with $6 \mathrm{~J}$ LLLT (AT+6 J); arthritis group treated with $10 \mathrm{~J}$ LLLT (AT+10 J). Results are expressed as mean \pm SEM
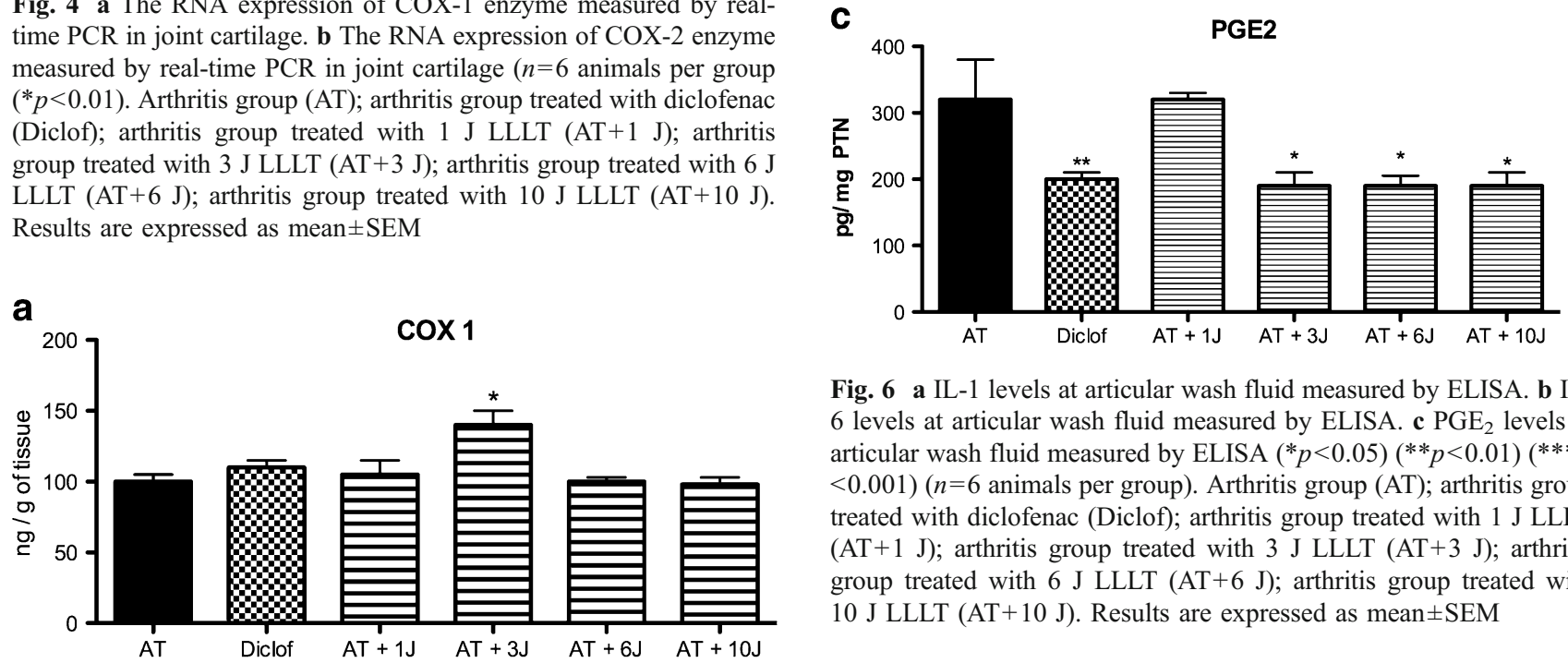

Fig. 6 a IL-1 levels at articular wash fluid measured by ELISA. b IL6 levels at articular wash fluid measured by ELISA. c PGE 2 levels at articular wash fluid measured by ELISA $\left({ }^{*} p<0.05\right)\left(*^{*} p<0.01\right)\left({ }^{* * *} p\right.$ $<0.001$ ) ( $n=6$ animals per group). Arthritis group (AT); arthritis group treated with diclofenac (Diclof); arthritis group treated with $1 \mathrm{~J}$ LLLT $($ AT $+1 \mathrm{~J})$; arthritis group treated with $3 \mathrm{~J}$ LLLT $(\mathrm{AT}+3 \mathrm{~J})$; arthritis group treated with $6 \mathrm{~J}$ LLLT $(\mathrm{AT}+6 \mathrm{~J})$; arthritis group treated with $10 \mathrm{~J}$ LLLT $(\mathrm{AT}+10 \mathrm{~J})$. Results are expressed as mean $\pm \mathrm{SEM}$

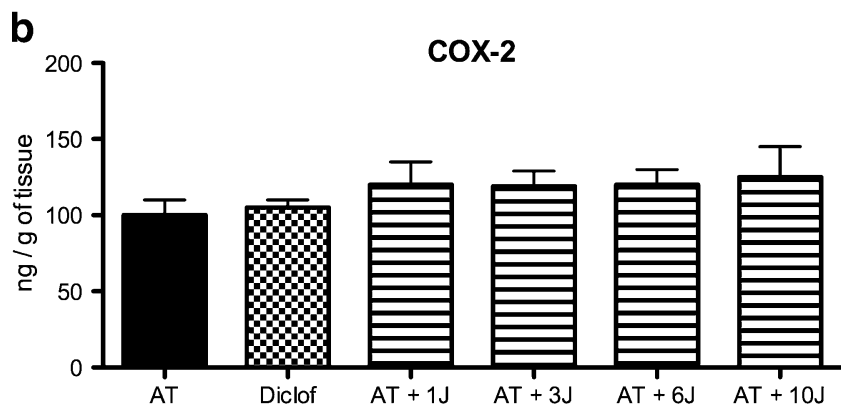

Fig. 5 a The COX-1 RNA expression measured by real-time PCR at articular wash fluid. b The COX-2 RNA expression measured by realtime PCR at articular wash fluid $\left({ }^{*} p<0.01\right)(n=6$ animals per group. Arthritis group (AT); arthritis group treated with diclofenac (Diclof); arthritis group treated with $1 \mathrm{~J}$ LLLT $(\mathrm{AT}+1 \mathrm{~J})$; arthritis group treated with $3 \mathrm{~J}$ LLLT $(\mathrm{AT}+3 \mathrm{~J})$; arthritis group treated with $6 \mathrm{~J}$ LLLT (AT+ $6 \mathrm{~J})$; arthritis group treated with $10 \mathrm{~J}$ LLLT $(\mathrm{AT}+10 \mathrm{~J})$. Results are expressed as mean \pm SEM

Prostaglandin $E_{2}$ The diclofenac and laser-treated groups $(3.0,6.0$, and $10.0 \mathrm{~J})$ presented a significant decrease of $\mathrm{PGE}_{2}$ levels when compared to the control group (Fig. 6c).

\section{Discussion}

Knee arthritis is a complex problem with a number of underlying cellular, biochemical, and physical causes. Leukocyte infiltration to the joint is a hallmark of arthritis. In our study, laser irradiation was significantly effective in reducing the total number of leukocytes as well as neutrophils in joint cavity. This fact was corroborated by the inhibition of myeloperoxidase activity that represents a chemical marker of neutrophil infiltration. 
In addition, proinflammatory mediators, including IL-1, tumor necrosis factor (TNF)- $\alpha$, and prostaglandins, are all over-produced in chondrocytes in pathological conditions and contribute to amplify the inflammatory process of the joint [13]. Cartilage extracellular matrix degradation and suppression of extracellular matrix biosynthesis are regulated by a significant increase in the levels of cytokines in the affected synovial joint [5].

IL-1 was originally detected in OA synovium [14, 15]. Only minimal IL-1 concentrations, particularly in its active form, were found in normal synovial fluid [4]. IL-1 was not detected in plasma even in patients with OA with prominent synovial fluid IL-1 levels, suggesting that IL-1 most likely acts locally and alters cartilage metabolism in OA synovial joints [16]. In our model of acute knee inflammation we could observe that LLLT was able to significantly reduce the concentration of IL- $1 \beta$ in joint wash fluid. These results are important, since IL-1 is implicated in cartilage degradation.

IL-6 was detected in patients with rheumatoid arthritis as well as in patients with osteoarthritis [5]. Some studies showed that IL-6 augmented MMP production while also inhibiting proteoglycan synthesis, increasing cartilage destruction [17]. From this point of view, LLLT was significantly effective in reducing IL-6 in joint wash fluid in our experimental model of joint inflammation which can indicate an effective reduction of joint cartilage degradation. We agree with the definition given by Brandt et al. [18] that $\mathrm{OA}$ as a joint inflammatory disorder is best defined as failed repair of damage that has been caused by excessive stress. In these cases, the innate mechanism of repairing the damage is not able to regenerate the cartilage. In fact, there is equilibrium between cell proliferation and death in healthy tissue. During joint diseases such as osteoarthritis, there will be a higher index of cell death, leading to cartilage and bone destruction and disability. IL-6 is also a key cytokine in this process by the stimulation of metalloproteinases.

Interestingly, COX-1 and COX-2 gene expression presented a tendency of increase in joint fluid after laser irradiation and a significant increase in joint cartilage after laser irradiation (Figs. 4, 5). However, $\mathrm{PGE}_{2}$ levels measured in joint wash fluid were inhibited. COX-2 was originally appointed as a target for antiinflammatory drugs. Suppression of the activity of this enzyme reduces edema formation and hyperalgesia. However, COX-2 is also a major contributor to the processes that leads to resolution of inflammation (for a review, see [18]). According to the author, injection of carrageenan into the rat paw produced edema formation with greatest increase in paw swelling typically seen $4-6 \mathrm{~h}$ after carrageenan administration. However, in wild-type mice, the swelling returned to its normal volume by 24 $48 \mathrm{~h}$ and in COX-2-deficient mice, the extent of paw edema was similar to that in wild-type mice, but the paw swelling failed to resolve even 1 week later. These findings indicate that in fact, COX-2 should play a pivotal role in resolution of inflammation.

Sehan et al. [19] demonstrated that aspirin (ASA) is unique among current pharmacological therapies because it acetylates cyclooxygenase COX-2 enabling the biosynthesis of R-containing precursors of endogenous antiinflammatory mediators. Our results show that even when COX-1 and COX-2 expression were enhanced by laser irradiation, all other inflammatory markers such as leukocyte infiltration, myeloperoxidase activity, IL-1, IL-6, and specially $\mathrm{PGE}_{2}$ were inhibited. These results lead us to suggest that laser radiation could be acting to modulate inflammatory process and possibly stimulating the production of antiinflammatory mediators.

Acknowledgments The authors would like to thank FAPESP for the research grants 2005/02117-6 and CAPES for the scholarship to Pallota R.

Open Access This article is distributed under the terms of the Creative Commons Attribution Noncommercial License which permits any noncommercial use, distribution, and reproduction in any medium, provided the original author(s) and source are credited.

\section{References}

1. Brandt KD, Dieppe P, Radin EL (2008) Etiopathogenesis of osteoarthritis. Rheum Dis Clin N Am 34:531-559

2. Martel-Pelletier J, Alaaeddine N, Pelletier JP (1999) Cytokines and their role in the pathophysiology of osteoarthritis. Front Biosci 4:D694-D703

3. Towle CA, Hung HH, Bonassar LJ et al (1997) Detection of interleukin-1 in the cartilage of patients with osteoarthritis: a possible autocrine/paracrine role in pathogenesis. Osteoarthritis Cartilage 5:293-300

4. Holt I, Cooper RG, Denton J et al (1992) Cytokine interrelationships and their association with disease activity in arthritis. Br J Rheumatol 31:725-733

5. Jikko A, Wakisaka T, Iwamoto $M$ et al (1998) Effects of interleukin-6 on proliferation and proteoglycan metabolism in articular chondrocyte cultures. Cell Biol Int 22:615-621

6. Ahrens D, Koch AE, Pope RM, Stein-Picarella M, Niedbala MJ (1996) Expression of matrix metalloproteinase 9 (96-kd gelatinase B) in human rheumatoid arthritis. Arthritis Rheum 39(9):1576-1587

7. Baker EA, Stephenson TJ, Reed MW, Brown NJ (2002) Expression of proteinases and inhibitors in human breast cancer progression and survival. Mol Pathol 55(5):300-304

8. Bensouyad A, Hollander AP, Dularay B, Bedwell AE, Cooper RA, Hutton CW, Dieppe PA, Elson CJ (1990) Concentrations of glycosaminoglycans in synovial fluids and their relation with immunological and inflammatory mediators in rheumatoid arthritis. Ann Rheum Dis 49(5):301-307

9. Bjordal JM, Johnson MI, Lopes-Martins RA, Bogen B, Chow R, Ljunggren AE (2007) Short-term efficacy of physical interventions in osteoarthritic knee pain. A systematic review and metaanalysis of randomised placebo-controlled trials. BMC Musculoskelet Disord 22(8):51 
10. Chow RT, Barnsley L (2005) Systematic review of the literature of low-level laser therapy (LLLT) in the management of neck pain. Lasers Surg Med 37(1):46-52

11. Chow RT, Johnson MI, Lopes-Martins RAB, Bjordal JM (2009) Efficacy of low-level laser therapy in the management of neck pain: a systematic review and meta-analysis of randomised placebo or active-treatment controlled trials. Lancet 374(9705):1897-1908

12. Bjordal JM, Johnson MI, Iversen V, Aimbire F, Lopes-Martins RA (2006) Photoradiation in acute pain: a systematic review of possible mechanisms of action and clinical effects in randomized placebo-controlled trials. Photomed Laser Surg 24(2):158-168

13. Aimbire F, Bjordal JM, Iversen VV, Albertini R, Frigo L, Pacheco MT, Castro-Faria-Neto HC, Chavantes MC, Labat RM, Lopes-Martins RA (2006) Low-level laser therapy partially restores trachea muscle relaxation response in rats with tumor necrosis factor alpha-mediated smooth airway muscle dysfunction. Lasers Surg Med 38(8):773-778

14. Goupille P, Mulleman D, Chevalier X (2007) Is interleukin-1 a good target for therapeutic intervention in intervertebral disc degeneration: lessons from the osteoarthritic experience. Arthritis Res Ther 9(6): 110

15. Haupt JL, Frisbie DD, McIlwraith CW, Robbins PD, Ghivizzani S, Evans CH, Nixon AJ (2005) Dual transduction of insulin-like growth factor-I and interleukin-1 receptor antagonist protein controls cartilage degradation in an osteoarthritic culture model. J Orthop Res 23(1):118-126

16. Ito A, Itoh Y, Sasaguri Y, Morimatsu M, Mori Y (1992) Effects of interleukin- 6 on the metabolism of connective tissue components in rheumatoid synovial fibroblasts. Arthritis Rheum 35(10):1197-1201

17. Madhok R, Crilly A, Watson J, Capell HA (1993) Serum interleukin 6 levels in rheumatoid arthritis: correlations with clinical and laboratory indices of disease activity. Ann Rheum Dis 52(3):232-234

18. Wallace JL (2006) COX-2: a pivotal enzyme in mucosal protection and resolution of inflammation. Sci World J 6:577-588

19. Serhan CN, Savill J (2005) Resolution of inflammation: the beginning programs the end. Nat Immunol 6(12):1191-1197 